\title{
IDENTIFICAÇÃO GEOFÍSICA DE ÁREAS DE ALTERAÇÃO HIDROTERMAL, CRIXÁS-GUARINOS, GOIÁS
}

\author{
AUGUSTO CÉSAR BITTENCOURT PIRES
}

\begin{abstract}
GEOPHYSICAL IDENTIFICATION OF HYDROTHERMALLY ALTERED AREAS, CRIXAS-GUARINOS, GOIAS. A large number of mineral deposits is associated to hydrothermal processes. In central Brazil important mineral occurrences, like the gold deposits of Crixas and Guarinos, are related to hydrothermalism. In this study we show how to identify areas that underwent hydrothermal influence, by analyzing airborne gamma-ray spectrometric data, specially the potassium channel. Unlike previous studies, we suppressed primary contribution to the natural gamma-ray field due to varying lithologies. environmental conditions, soil types, and observing geometry. After suppressing the primary contribution, secondary accumulations of potassium, most of them related to hydrothermal processes, can be easily observed. Suppression is conducted by normalizing potassium to the thorium data. Differences between predicted and actual potassium values indicate areas of excess accumulation. Similar procedure was conducted for uranium. Contour maps of deviations observed for potassium and uranium for Crixas and Guarinos indicate areas of anomalous accumulations of these elements. The anomalies correspond to hydrothermally altered areas. Well known mineral occurrences, as the gold deposits of Crixas and Guarinos, are clearly associated to the potassium anomalies revealed by the proposed procedure.
\end{abstract}

Keywords: hydrothermally altered areas, geophysics, gamma-ray spectrometry, mineralizations.

\begin{abstract}
RESUMO Um grande número de depósitos minerais está associado a processos hidrotermais. Na região central do Brasil jazimentos importantes, como as ocorrências de ouro de Crixás e Guarinos, Goiás, têm sua origem associada ao hidrotermalismo. Neste estudo mostramos como áreas submetidas a ação de processos hidrotermais e possuindo expressão em superfície podem ser identificadas através da análise de dados gama-espectrométricos, especialmente para o canal do potássio. Diferentemente dos estudos anteriores, efetuamos a supressão das contribuições primárias ao campo natural de radiação gama devido às variações de litologia, condições ambientais, tipos de solo e geometria de observação. Deste modo acumulações secundárias de potássio podem ser mais facilmente observadas. A supressão é efetuada através da normalização dos dados de potássio em função dos valores de tório. A diferença entre valores previstos de potássio e valores realmente medidos indicam áreas de acumulação secundária deste elemento. Procedimento similar foi conduzido para o urânio. Mapas de contorno dos desvios na acumulação de potássio e urânio para as áreas de Crixás e Guarinos indicam regiões de acumulação anômala destes elementos. Estas regiões estão associadas a áreas de conhecida influência hidrotermal. Jazimentos conhecidos na região, especialmente mineralizações de ouro, estão claramente associados às concentrações anômalas de potássio.
\end{abstract}

Palavras-chave: áreas hidrotermalizadas, geofísica, espectrometria de radiação gama, mineralizações.

INTRODUÇÃo Um grande número de depósitos minerais está associado a processos hidrotermais. A gama de jazimentos de origem hidrotermal abrange desde aqueles vulcanogênicos próximos e distantes até os depósitos filoneanos, incluindo os apicais disseminados, os escarníticos e os pegmatíticos (Biondi 1986).

Jazimentos minerais importantes na região central do Brasil estão associados ao hidrotermalismo (Suszczynski 1973, Branco 1984, Thomson 1986 e 1991, Pulz 1990). Dentre estes depósitos estão as conhecidas mineralizações de ouro de Crixás e Guarinos, Goiás.

Observações diretas e indiretas revelam que as soluções hidrotermais seriam compostas principalmente de silica, os cations $\mathrm{Na}, \mathrm{K}, \mathrm{Ca}$ e $\mathrm{Mg}$ e os ânions $\mathrm{Cl}, \mathrm{SO} 4$ e $\mathrm{HCO}$. A estes componentes seriam adicionados os metais e enxofre, necessários à formação dos minerais de minérios (Krauskopf 1967). O potássio 40 , constituinte importante das soluções hidrotermais, é o principal contribuinte e responsável por 98\% da emissão de radiação gama dos radio-isótopos primários presentes na crosta terrestre. Sua contribuição ao espectro natural de radiação gama pode ser facilmente observada através dos aerolevantamentos (Adams \& Gasparini 1970). Urânio e tório, outros dois importantes radioelementos pre- sentes na crosta terrestre, devido a pequena abundância, número atômico elevado, alta Valencia e eletronegatividade, tendem a ser concentrados no líquido residual durante o processo de cristalização e, assim, são freqüentemente incorporados aos últimos estágios da diferenciação magrnática (Adams \& Gasparini 1970). Na área de estudo, entretanto, não existe qualquer referência a acumulação de urânio e tório associada a processos hidrotermais.

$\mathrm{O}$ reconhecimento de áreas resultantes ou sob influência de processos hidrotermais é grandemente relevante para a prospecção mineral. Até recentemente este esforço era desenvolvido através do mapeamento geológico. Atualmente, a utilização de dados de sensoriamento remoto e aerogeofísica tem sido proposta (Rowan et al 1977, Ferreira Jr. 1993, Santos Filho et al. 1994, Araújo 1994). O uso de dados de imagens obtidas por satélite é dificultado pelo intenso processo de alteração das rochas observado na região central do País (Ferreira Jr. 1993). Santos Filho e colaboradores (1994) usaram dados aeromagnéticos e aero-gamaespectrométricos visando caracterizar zonas hidrotermalizadas. A não correção dos dados originais para o efeito do background geológico prejudica uma definição adequada das zonas hidrotermalizadas. 
No estudo que apresentamos a seguir efetuamos uma análise dos dados de espectrometria gama obtidos pelo Projeto Geofísico Brasil-Canadá-PGBC, (Carmo 1978), para as regiões de Crixás e Guarinos, Goiás. Com a supressão nos registros do efeito provocado por variações litológicas, de tipos de solos e ambientais é possível a identificação mais precisa das acumulações anômalas de potássio. A associação das ocorrências de ouro e outros bens minerais, de origem hidrotermal., com estas zonas anômalas é evidente.

GEOLOGIA REGIONAL As associações litológicas presentes na região são representadas por terrenos granitogreenstones de idade arqueana e uma unidade metassedimentar mais jovem, denominada Seqüência Morro Escuro (Jost et al. 1989). Estes terrenos são cobertos a norte e a sul por metassedimentos proterozóicos do Grupo Araxá, através de falhas de empurrão.

Os greenstone belts são representados por três faixas sub-paralelas, estreitas e alongadas no sentido N-S, estendendo-se por cerca de $40 \mathrm{~km}$ de comprimento e de até $20 \mathrm{~km}$ de largura, embora a média esteja entre 4 e $8 \mathrm{~km}$ (Marini et al. 1984). As faixas denominadas de oeste para leste de greenstone belt de Crixás, greenstone belt de Guarinos e greenstone belt de Pilar de Goiás-Hidrolina, estão separadas entre si por blocos granito-gnáissicos. O Bloco de Caiamar separa as faixas de Crixás e Guarinos e o Bloco de Moquém, as faixas Guarinos e Pilar de Goiás-Hidrolina. O Bloco da Anta e o Domo de Hidrolina correspondem aos extremos oeste e leste da área, respectivamente (Fig. 1).

As relações de contato entre os blocos granito-gnáissicos e supracrustais são inteiramente por extensas zonas de cisaIhamento e as foliações presentes nos gnaisses e supracrustais são perfeitamente concordantes (Vargas 1992). No entanto, no contato entre o Bloco Caiamar e a parte NE do greenstone belt de Guarinos evidenciou-se metamorfismo de contato através de sericitização e carbonatação na seqüência supracrustal, evidenciando o contato localmente intrusive.

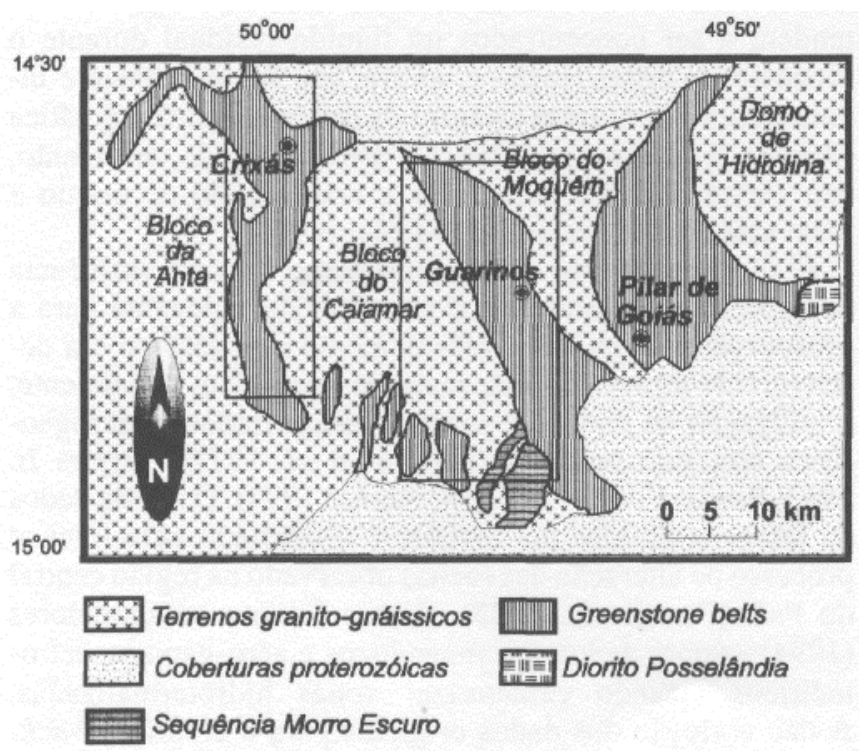

Figura 1 -Esboço geológico da região de Crixás-Guarinos, Goiás. Áreas de estudo indicadas no mapa

Figure 1 - Geological lay-out in the region of Crixás-Guarinos, Goiás. Study areas indicated in the map
O Bloco da Anta é constituído por grandioritos e tonalitos gnaissificados sendo que o primeiro predomina na porção norte. Contrariamente, o Bloco de Caiamar tem uma predominância de granodiorito ao sul e tonalitos no centro e norte (Vargas 1992). Segundo Jost et al. (1994), o Bloco de Caiamar é um complexo de gnaisses (Gnaisse Crixás-Açu), tonalitos (Tonalito Tocambira) e granodioritos (Granodiorito Águas Claras), localmente migmatitos e diques de diabásio, propondo, assim, a denominação de Complexo Caiamar.

O Bloco de Moquém é composto por gnaisses graníticos e tonalíticos (Danni \& Ribeiro 1978, Vargas 1992), migmatitos (Vargas 1992), e gnaisses granodioríticos, um stock tonalítico e diques básicos (Jost et al. 1994). Segundo Jostef ai. (1994), o Bloco de Moquém pode ser dividido em 2 ciclos. O primeiro representado por ortognaisses tonalíticos, granodioríticos e graníticos, intrudidos por um enxame de diques básicos, antes da deformação e do pico do metamorfismo em fácies anfibolito. $\mathrm{O}$ segundo ciclo é representado por pequenas intrusões tonalíticas com novas gerações de diques básicos. Metamorfismo no fácies xisto-verde afetou todas as unidades do Bloco no Arqueano e Neoproterozóico.

O Domo de Hidrolina é constituído predominantemente por gnaisses de natureza granodiorítica, com intercalações pegmatíticias e graníticas (Vargas 1992). No interior do Domo de Hidrolina ocorrem intrusões de granito potássico associado a um sistema de falhas transcorrentes NW, denominado Zona de Falha Taquaruçu por Danni et al (1978).

As unidades supracrustais foram divididas por Jost et al. (1991) em três faixas: Grupo Pilar de Goiás, Grupo Guarinos e Grupo Crixás. As características principais de cada unidade são apresentadas a seguir.

O Grupo Pilar de Goiás foi dividido em Formação Córrego Fundo (metakomatiítos com intercalações de formação ferrífera bandada), Formação Cedrolina (metabasaltos de composição toleítica com intercalações de formação ferrífera bandada), Formação Boqueirão (meta-chert, mármores e calci-silicatadas) e Formação Serra do Moinho (filitos carbonosos, sericita-clorita filitos e finas intercalações de formação ferrífera e/ou manganesífera bandadas).

O Grupo Guarinos é representado pela Formação Serra do Cotovelo (metakomatiítos, serpentinitos, talco xistos e filitos carbonosos), Formação Serra Azul (metabasaltos, anfibolitos e intercalações de filitos e xistos carbonosos), Formação São Patricinho (meta-grauvacas com ocasionais intercalações de formação ferrífera bandada, filitos carbonosos e meta-basaltos), Formação Aimbé (formação ferrífera bandada) e Formação Cabaçal (quatzo-sericita e quartzosericita-clorita filitos com proporções variáveis de material carbonoso).

O Grupo Crixás compreende a Formação Córrego Alagadinho (metakomatítos com intercalações de formação ferrífera bandada e diques e soleiras de peridotitos e piroxenitos), Formação Rio Vermelho (meta-basaltos com intercalações de formação ferrífera e/ou manganesífera bandada e dique e soleiras de gabros e peridotitos) e Formação Ribeirão das Antas (filitos carbonosos com intercalações de metachert e lentes de mármores, metagrauvacas, filitos com granadas e localmente filitos com cloritóides).

A Seqüência Morro Escuro, de idade provável entre o final do Arqueano e Proterozóico Inferior, aflora ao sul de Guarinos e na Serra das Figas. É representada por metas- 
sedimentos químicos suborizontais com ocasionais lentes de fácies detríticas sobrepostas às rochas gnáissicas $Q$ greenstone belts, acima destas encontram-se os metassedimentos do Grupo Araxá.

\section{SUPRESSÃO DAS CONTRIBUIÇÕES PRIMÁRIAS}

Durante o desenvolvimento do PGBC na região em apreço, foram executadas linhas de vôo na direção N-S espaçadas entre si de aproximadamente $1 \mathrm{~km}$. Com a aeronave ${ }^{\wedge} \hat{o} a n d o$ a uma altura média do terreno de $150 \mathrm{~m}$, foram efetuadas medidas magnéticas e gama-espectrométricas. O registro da radiação natural proveniente do solo contemplou as contribuições do urânio, tório e potássio. A contagem total de radiação na faixa de energia de interesse também foi registrada (Carmo 1978). Os sistemas gama-espectrométricos utilizados durante o PGBC foram calibrados segundo procedimento descrito por Darnley \& Grasty (1971) permitindo, deste modo, que as contagens registradas para cada ponto ao longo da linha de vôo fossem convertidas em ppm equivalente de urânio e tório, e porcentagem de potássio.

A partir dos registros digitais produzidos durante o PGBC foram obtidos os valores, em ppm equivalente no solo, de urânio e tório e porcentagem de potássio para as duas áreas de interesse: Crixás e Guarinos. Os dados originais foram interpelados para uma malha regular de $500 \mathrm{~m}$ de lado por intermédio de krigagem e um padrão elíptico de procura de pontos (Davis 1986). Neste estágio poderiam ser construídos mapas de isovalores mostrando as concentrações dos elementos radioativos nas áreas de interesse. Entretanto, as variações de concentração dos elementos refletem vários fatores.

A litologia superficial é o principal fator que influencia na variação do teor de radioelementos nas rochas. Deste modo é necessário suprimir os efeitos provocados por variações litológicas ou tipos de solos e as condições ambientais antes de se avaliar qualquer outro efeito secundário (Foote 1969). Diversos procedimentos têm sido propostos visando a supressão dos efeitos litológicos e ambientais (Saunders et al 1978, 1987, 1993, 1994, Galbraith \& Saunders 1983). A maior parte destes estudos visava a identificação de acumulações de petróleo e nenhum a identificação de depósitos hidrotermais, a partir da análise de dados gama-espectrométricos.

Segundo a proposta de Saunders et al. (1987) os teores de tório são usados como controle litológico para definir valores ideais de urânio e potássio para cada amostra. A idéia central é de que os efeitos litológicos e ambientais que influenciam a concentração aparente de tório também afetam urânio e potássio de modo previsível (Saunders et al 1993). Os dados da Tabela 1 mostram que mudanças em litologia resultam em aumentos ou diminuições simultâneas e da mesma ordem nos três elementos. Adicionalmente, conforme indicado por Norwine et al (1980) e Travassos \& Pires (1994) umidade do solo e biomassa causam absorção de radiação gama. Entretanto, esta absorção é similar para os três elementos de interesse em gamaespectrometria. $\mathrm{O}$ mesmo pode ser considerado para as variações decorrentes das mudanças na geometria de observação, provocadas por irregularidades no relevo topográfico (Ward 1981).

Devido as similaridades no comportamento e, como na área de estudo não existem efeitos secundários na acumulação de tório associados a processos hidrotermais, reportados
Tabela 1 - Concentração média dos radio-elementos nas rochas (Hansen 1975). * Potássio químico contém 0,012\% de $K^{40}$

Table 1 - Average concentration of radioactive elements in rocks (Hansen 1975). * Chemical potassium contain $0.012 \%$ of $\mathrm{K}^{40}$

\begin{tabular}{rlll}
\hline & ${ }^{*} \mathrm{~K}^{40} \mathrm{ppm}$ & $\mathrm{Th}^{232} \mathrm{ppm}$ & $\mathbf{U}^{233} \mathrm{ppm}$ \\
Rochas básicas & & & \\
média & 0.8 & 4.0 & 1.0 \\
faixa & $0.2-2.0$ & $0.5-10.0$ & $0.2-4.0$ \\
Rochas graníticas & & & \\
média & 3.0 & 12.0 & 3.0 \\
Folhelhos & & & \\
média & 2.7 & 12.0 & 3.0 \\
faixa & $1.6-4.2$ & $8.0-18.0$ & $1.5-5.5$ \\
Arenitos & & & \\
média & 1.1 & 1.7 & 0.5 \\
faixa & $0.7-3.8$ & $0.7-2.0$ & $0.2-0.6$ \\
Carbonatos & & & \\
média & 0.3 & 1.7 & 2.2 \\
faixa & $0.0-0.2$ & $0.1-7.0$ & $0.1-9.0$ \\
\hline & & &
\end{tabular}

na literatura ou aparentes numa inspeção visual dos dados, a normalização dos dados para este elemento suprimiria os efeitos primários de todas as variáveis indesejáveis.

Como decorrência das considerações aqui efetuadas, valores de tório podem ser usados para prever potássio, a partir da determinação das relações regionais entre os dois elementos. Diferença entre valores previstos de potássio e valores realmente medidos poderiam ser causadas por outros fatores que não a litologia, biomassa, umidade do solo ou geometria de observação. A utilização do tório, e não do urânio, para a estimativa de valores ideais de potássio se deve ao fato deste elemento, o tório, ter menor mobilidade geoquímica (Adams \& Gasparini 1970).

PROCESSAMENTO E INTERPRETAÇÃO DOS DADOS Os dados gama-espectrométricos digitais de urânio, tório e potássio registrados para cada linha de vôo do PGBC foram reprocessados visando colocá-los em malha regular de $500 \mathrm{~m}$ de lado. Para a área de Crixás foram utilizadas 15 linhas de vôo e 25 em Guarinos.

Devido a processos inadequados de correção do background atmosférico e/ou calibração instrumental usados no PGBC, concentrações negativas dos radio-elementos são observadas nos dados. Este problema foi sanado com a adição a cada observação do valor correspondente ao menor valor negativo observado para um dado elemento. Deste modo, o menor valor de cada conjunto de observações de um dado radio-elemento passou a ser zero.

A partir dos dados corrigidos procurou-se determinar a correlação entre os valores de tório e potássio para cada uma das duas áreas em estudo. As figuras 2 e 3 mostram os gráficos obtidos com a plotagem dos valores de tório versus potássio para as áreas de Crixás e Guarinos. Conforme também observado por Saunders et al (1994), a dependência da concentração do potássio com relação ao tório é representada por uma função linear que passa pela origem. A inclinação da reta é determinada pela razão entre os valores das observações de potássio $\left(\mathrm{K}_{\mathrm{s}}\right)$ e os de tório $\left(\mathrm{Th}_{\mathrm{s}}\right)$. Caso exista interesse em estudar o comportamento do urânio, procedi- 


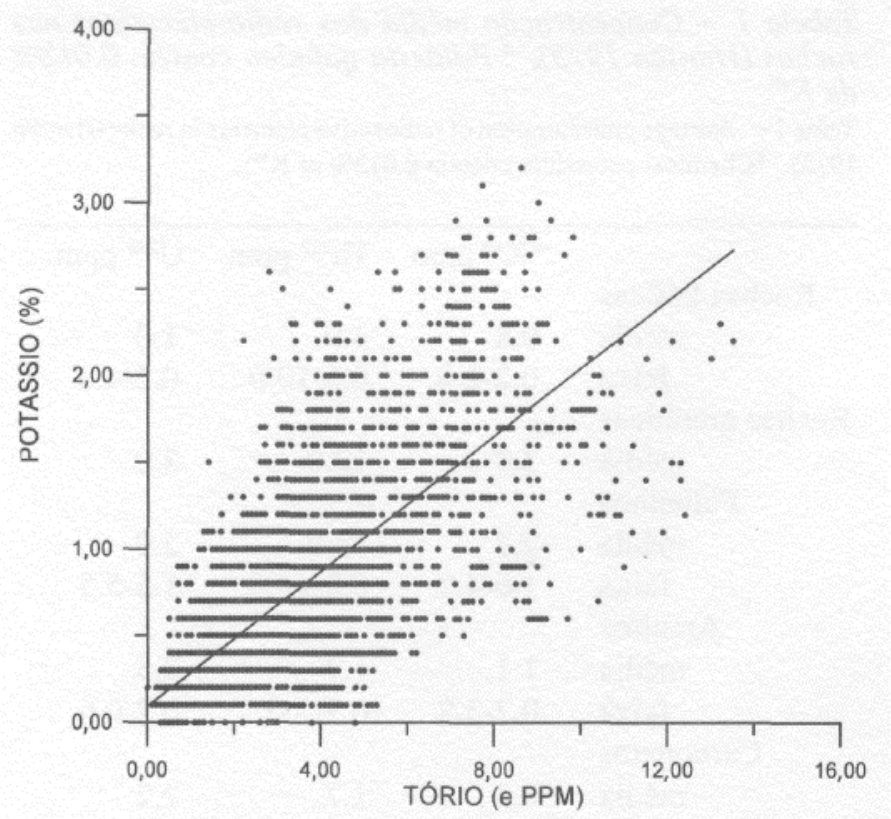

Figura 2 - Gráfico dos valores de tório e potássio para todos os pontos de observação na área de Crixás. Reta que melhor se ajusta ao conjunto de dados indicada no gráfico Figure 2 - Thorium and potassium cross-plot for all observation points in the Crixás area. Best fitted line indicated in the graph

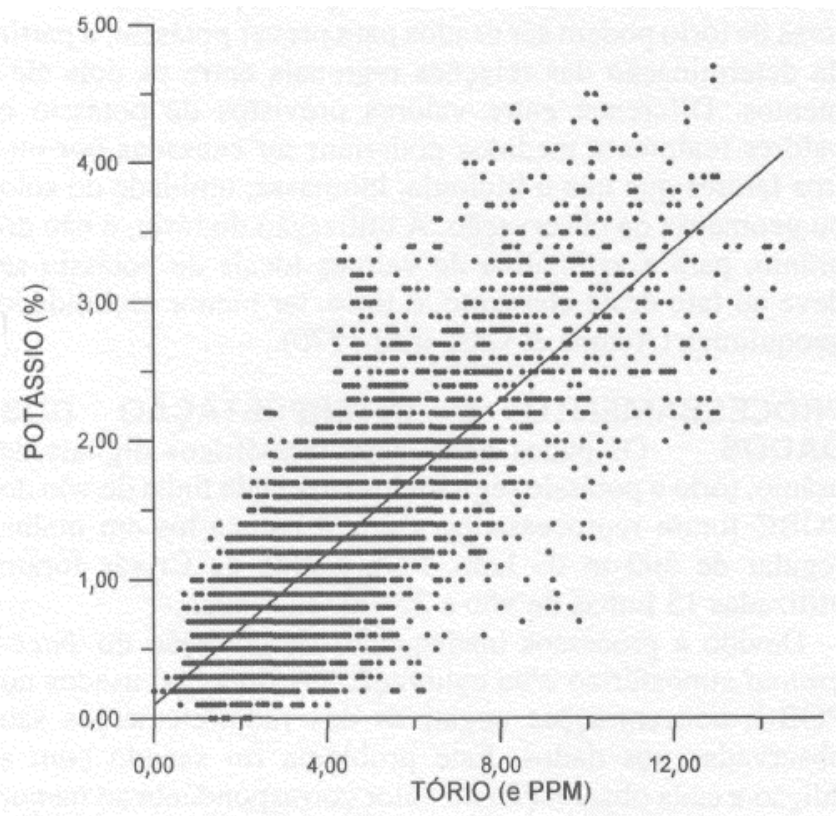

Figura 3- Gráfico dos valores de lório e potássio para todos os pontos de observação na área de Guarinos. Reta que melhor se ajusta ao conjunto de dados indicada no gráfico

Figure 3 - Thorium and potassium cross-plot for all observation points in the Guarinos area. Best fitted line indicated in the graph

mento análogo deve ser desenvolvido para este radio-elemento. Para o potássio temos a relação:

$\mathrm{K} ;=\left(\right.$ média de $\mathrm{K}_{\mathrm{s}} /$ média de $\left.\mathrm{Th}_{\mathrm{s}}\right) \mathrm{x} \operatorname{Th}(1)$

onde $\mathrm{K}_{\mathrm{I}}$ é o valor ideal de potássio, definido a partir da concentração de tório para aquele ponto de observação.
Os desvios dos valores reais a partir dos valores ideais, calculados para cada ponto, foram obtidos usando a equação:

$$
\mathrm{K}_{\mathrm{d}}=\left(\mathrm{K}_{\mathrm{s}}-\mathrm{K}_{\mathrm{i}}\right) / \mathrm{K}_{\mathrm{i}}
$$

Os desvios observados para potássio $\left(\mathrm{K}_{\mathrm{d}}\right)$ para as áreas de Crixás e Guarinos foram contornados e estão apresentados nas figuras 4 e 5 . Nestas figuras estão também

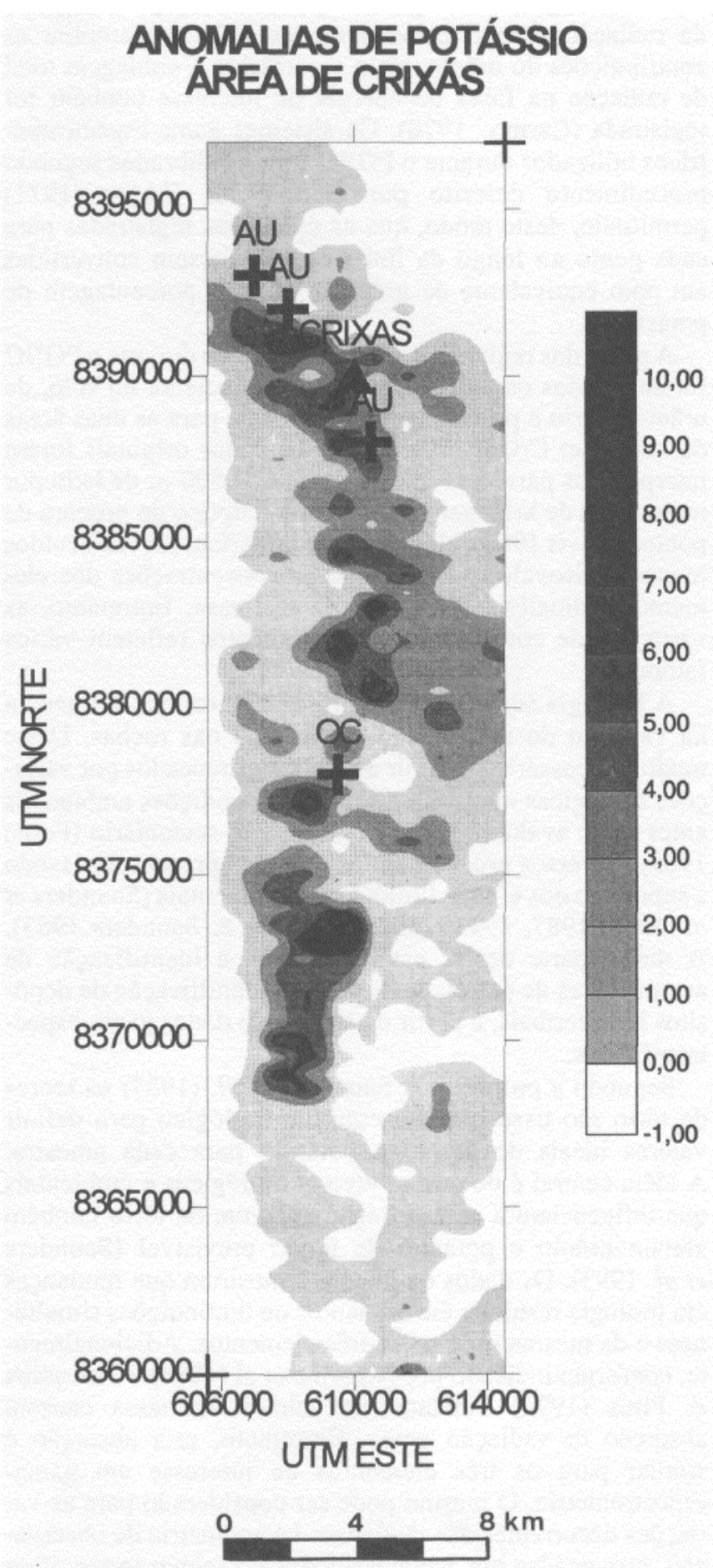

Figura 4-Anomalias de potássio para a área de Crixás. Mineralizações de origem hidrotermal indicadas no mapa Figure 4 - Potassium anomalies in the Crixás area. Mineralizations of hydrothermal origin indicated in the map 


\section{ANOMALAS DE POTÁSSIO ÁREA DE GUARINOS}

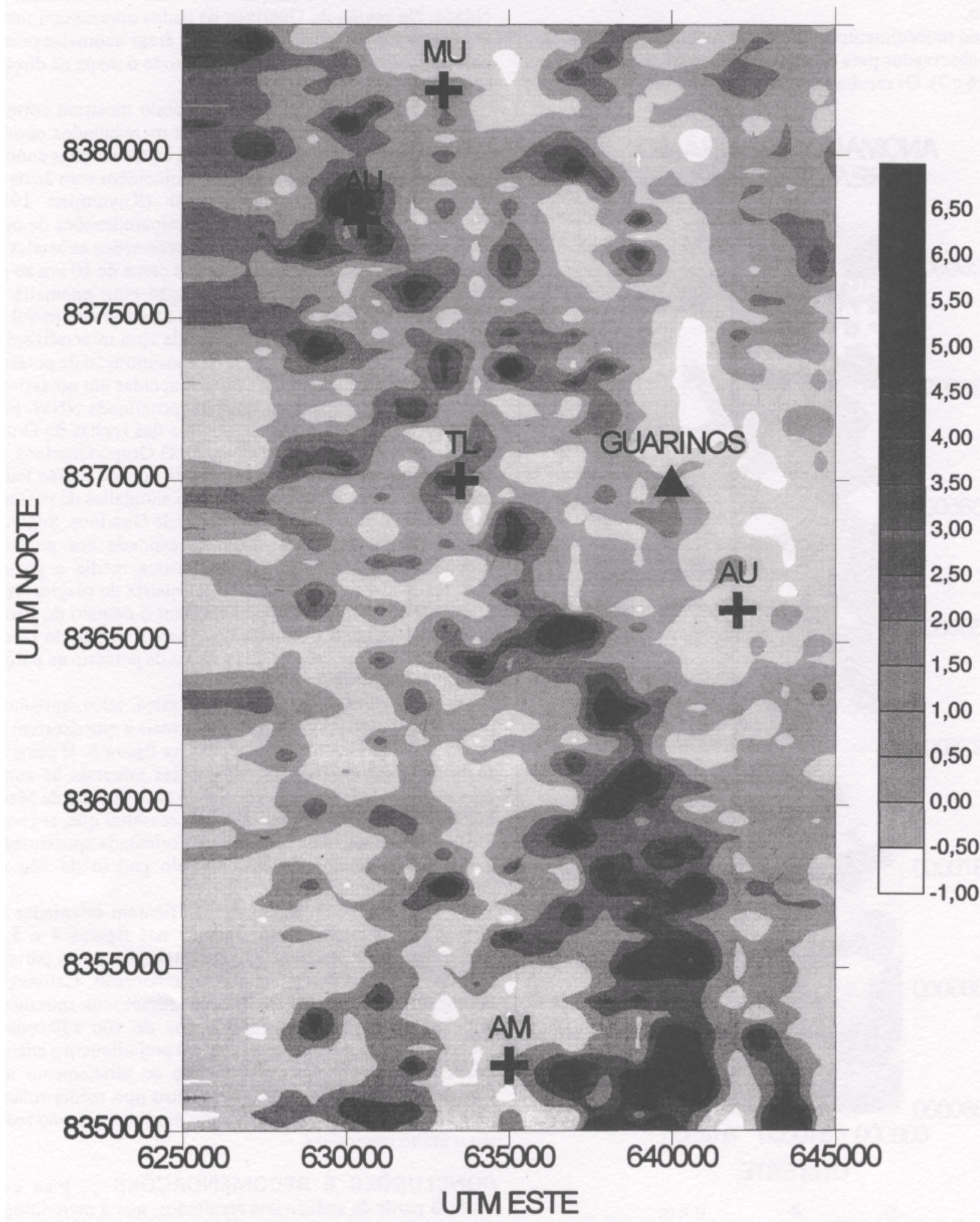

0

$20 \mathrm{~km}$

Figura 5-Anomalias de potássio para a área de Guarinos. Mineralizações de origem hidrotermal indicadas no mapa Figure 5 - Potassium anomalies in the Guarinos area. Mineralizations of hydrothermal origin indicated in the map 
indicadas as mineralizações conhecidas resultantes de processos hidrotermais. Mineralizações de ouro (AU), talco (TL), amianto (AM) e mica (MU) e ocorrência de cobre, níquel, cobalto e cromo associados $(\mathrm{OC})$ estão presentes na região.

Usando procedimento análogo apresentamos, também, os desvios observados para o urânio nas duas áreas de interesse (figuras 6 e 7). Os resultados obtidos com urânio não são tão

\section{ANOMALAS DE URÂNIO ÁREA DE CRIXÁS}

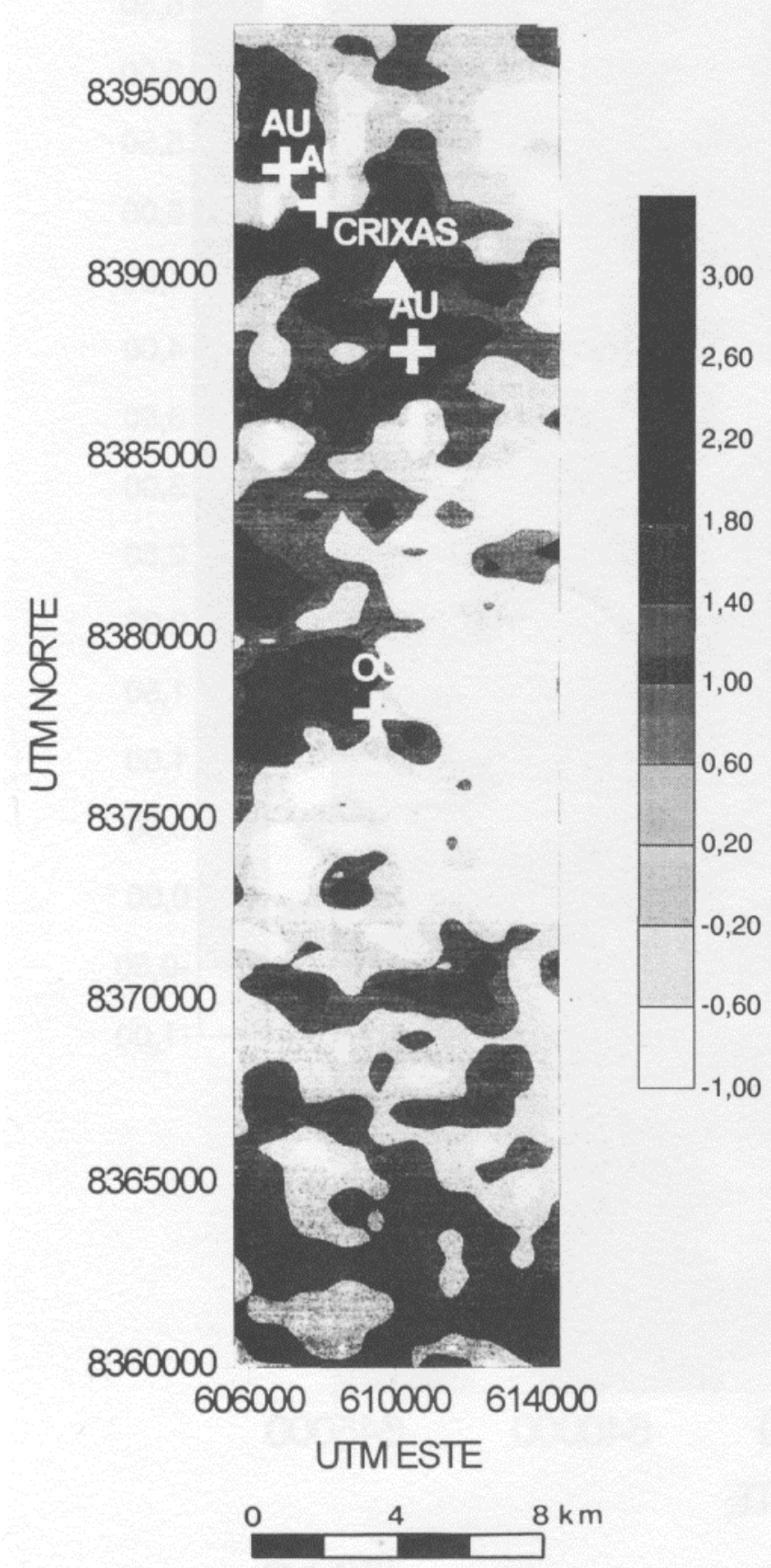

Figura 6 - Anomalias de urânio para a área de Crixás. Mineralizações de origem hidrotermal indicadas no mapa

Figure 6 - Uranium anomalies in the Crixás area. Mineralizations of hydrothermal origin indicated in the map expressivos quanto aqueles obtidos para o potássio. Para cada uma das áreas estudadas, entretanto, fica indicada a presença de zonas anômalas. $\mathrm{Na}$ área de Crixás as anomalias ficam localizadas na porção centro-sul e a noroeste da cidade. Na região de Guarinos os dados apresentam maior espalhamento estando, entretanto, as áreas anômalas principais dispostas numa faixa que cruza todo o mapa na direção SE/NW.

Os resultados obtidos para o potássio mostram correlações importantes. A figura 4 mostra os resultados obtidos para a área de Crixás. As regiões com concentrações anômalas de potássio em torno de Crixás coincidem com áreas de reconhecida influência hidrotermal (Kuyumjian 1981, Thonsom 1986, 1991). Conhecidas mineralizações de ouro na área têm e correlação com as concentrações anômalas de potássio. Ocorrência de metais base a cerca de $10 \mathrm{~km}$ ao sul de Crixás também está em associação com anomalia de potássio. Forte anomalia de potássio na parte centro-sul do mapa não possui correlação conhecida com mineralização.

A figura 5 mostra os desvios na concentração de potássio para a área de Guarinos. Áreas enriquecidas em potássio se localizam numa faixa com direção aproximada NNW. Esta faixa corresponde a região de contato das rochas do Grupo Guarinos com o Complexo Caiamar. O Grupo Guarinos, na região, é representado pelas rochas da Formação São Patricinho e Serra Azul. Outra região com anomalias de potássio se dispõe em forma de arco a NE e N de Guarinos. Segundo Jost et al. (1994) esta região corresponde aos gnaisses granodioríticos de textura granoblástica média a grossa, com fenoclastos de K-feldspato em matriz de plagioclásio, quartzo e biotita. Estas rochas formam o contato do Bloco do Moquém com o Domo de Guarinos. A região do Domo corresponde a área com baixos valores de potássio na porção central superior da figura 5 .

As conhecidas mineralizações de mica, talco, amianto e ouro, vinculadas à processos hidrotermais e que ocorrem na região de Guarinos estão indicadas na figura 5. E possível observar a associação das ocorrências minerais às zonas com valores elevados de potássio. No caso do ouro de Maria Lázara, ao sul de Guarinos, devemos ressaltar que, segundo Pulz (1990), trata-se de faixa estreita orientada aproximadamente NS e de difícil detecção pelo padrão de vôo do aerolevantamento.

A tendência de certas anomalias ficarem orientadas na direção NS, especialmente evidente nas figuras 4 e 5 , é devido, em parte, a orientação das litologias e, em parte, a problemas operacionais do aerolevantamento. Calibração deficiente dos sistemas gama-espectrométricos introduziu um desnível sistemático entre linhas de vôo adjacentes. Embora as variações introduzidas não prejudiquem a análise dos dados, elas geram certo padrão de alinhamento nas curvas de contorno. $\mathrm{O}$ uso de um filtro tipo média-rolante aplicado transversalmente à direção das linhas de vôo reduziu o efeito observado.

CONCLUSÕES E RECOMENDAÇÕES Fica evidente, a partir da análise dos resultados, que a metodologia aqui proposta consegue revelar acumulações anômalas de potássio. Estas acumulações, em grande maioria, são associadas a processos de enriquecimento ou alterações de origem hidrotermal. O procedimento pode ser efetuado com o urânio, embora com resultados menos expressivos.

Depósitos minerais da região, de reconhecida influência hidrotermal., estão associados à zonas de acumulação ano- 


\section{ANOMAUAS DE URÂNIO ÁREA DE GUARINOS}

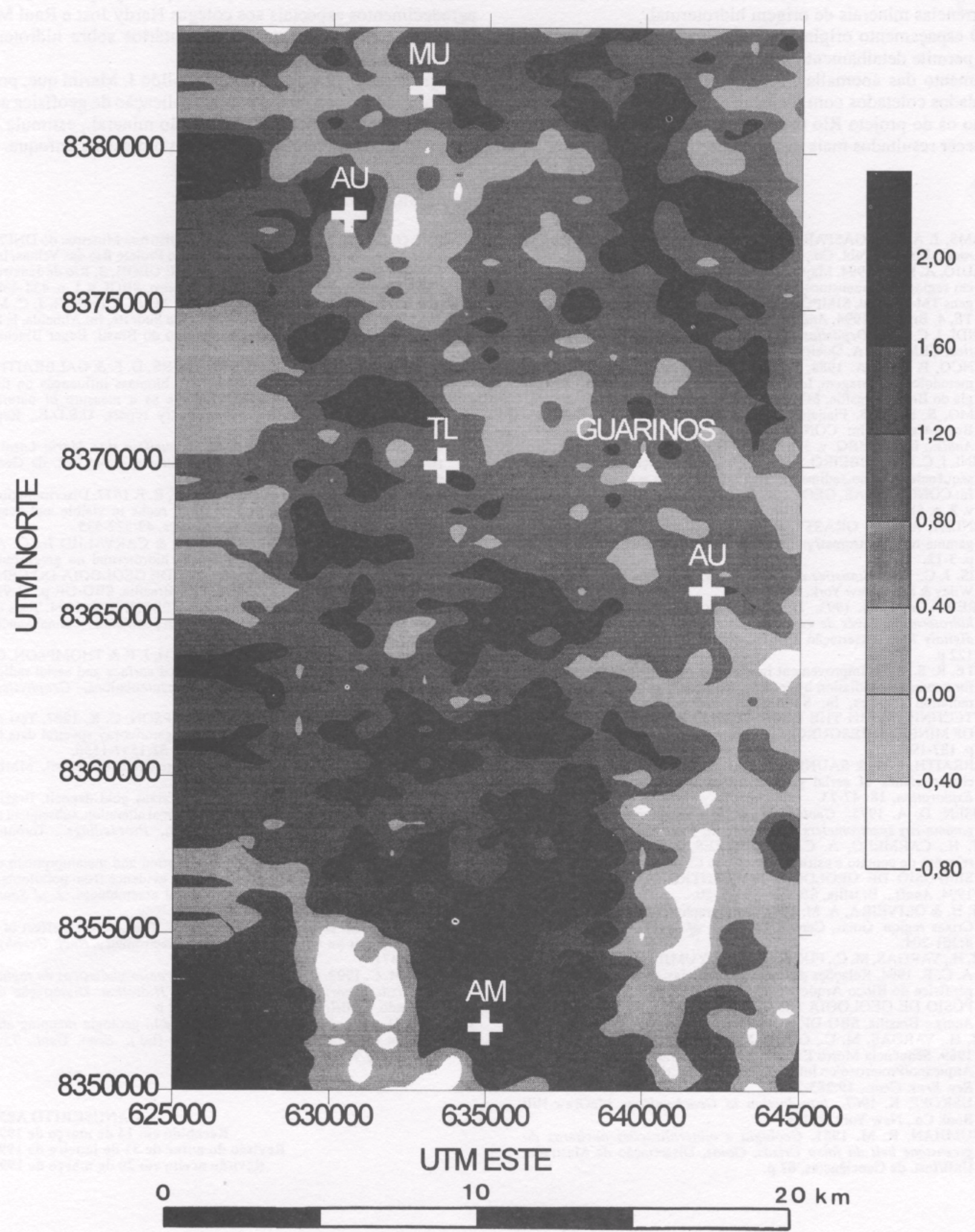

Figura 7 -Anomalias de urânio para a área de Guarinos. Mineralizações de origem hidrotermal indicadas no mapa Figure 7 - Uranium anomalies in the Guarinos area. Mineralizations of hydrothermal origin indicated in the map 
mala de potássio. Deste modo, esta metodologia serve para indicar alvos potenciais para a prospecção mineral na região. Seria recomendado o uso desta metodologia em áreas da região amazônica de difícil acesso e com reconhecidas ocorrências minerais de origem hidrotermal.

$\mathrm{O}$ espaçamento original de $1 \mathrm{~km}$ entre as linhas de vôo não permite detalhamento maior das feições e provoca deslocamento das anomalias. A utilização desta metodologia em dados coletados com maior densidade de linhas de vôo, como os do projeto Rio das Velhas, (Marini 1993), poderá fornecer resultados mais interessantes.
Agradecimentos Agradecemos ao DNPM e à CPRM pelo fornecimento dos dados digitais do PGBC que têm permitido a obtenção de interessantes resultados, após mais de 20 anos da realização daquele projeto. Nossos agradecimentos especiais aos colegas Hardy lost e Raul M. Kuyumjian pelos ilustrativos comentários sobre hidrotermalismo na região de Crixás.

Agradecemos, ainda, ao amigo Onildo J. Marini que, por suas constantes indagações sobre a aplicação de geofísica ao mapeamento geológico e à prospecção mineral., estimula o pesquisador a produzir trabalhos com o presente enfoque.

\section{REFERÊNCIAS BIBLIOGRÁFICAS}

ADAMS, J. A. S. \& GASPARINI, P. 1970. Gamma-ray spectrometry of rocks, Elsevier Publ. Co., New York, 295 p.

ARAÚJO, A. H. de. 1994. Mapeamento de zonas de alteração hidrotermal em regiões de greenstone belt através da técnica SCPFO para imagens TM-Landsat, SIMPÓSIO DE GEOLOGIA DO CENTRO-OESTE, 4, Brasília, 1994, Anais..., p. 195-197.

BIONDI, J. C. 1986. Depósitos de minerais metálicos de filiação magmafica, CBMM- T. A. Queiroz Ed., S. Paulo, 602 p.

BRANCO, P. C. de A. 1984. Principais depósitos minerais: conceitos, metodologia e listagem. In: Schobbenhaus, C. et al. (Coord.), Geologia do Brasil, Brasília, MME/DNPM, p. 359-419.

CARMO, S. D. 1978. Planejamento e execução do Projeto Geofísico Brasil-Canadá, In: CONGR. BRAS. GEOL., 30, Recife, 1978. Anais... Recife, SBG. v. 5, p. 2233-2247.

DANNI, J, C. M. \& RIBEIRO, C, C. 1978. Caracterização estatigráfica da seqüência vulcano-sedimentar de Pilar de Goiás e Guarinos, Goiás, In: CONGR. BRÁS. GEOL., 30, Recife, 191\&, Anais... Recife, SBG. v. 2 , p. $582-596$

DARNLEY, A. G. \& GRASTY, R. L. 1971. Mapping from ther air by gamma-ray spectrometry: Can. Inst. Min. Metallurg., Spec. v. 11, p. 3-12.

DAVIS, J. C. 1986. Statistics and data analysis in Geology, 2 ed., John Wiley \& Sons, New York, $646 \mathrm{p}$.

FERREIRA Jr., L. G. 1993. Discriminação de produtos de alteração hidrotermal através de espectrorradiometria $e$ análise de imagens digitais TM, Dissertação de Mestrado, UnB/Inst. de Geociências, $122 \mathrm{p}$.

FOOTE, R. S. 1969. Improvement in airborne gamma-radiation analysis for anomalous radiation by removal of environmental and pedologic radiation changes. In: SYMPOSIUM ON USE OF NUCLEAR TECHNIQUES IN THE PROSPECTING AND DEVELOPMENT OF MINERAL RESOURCES. 1. Viena, 1969. Proceedings... Viena, p. 187-194.

GALBRAITH. J. H. \& SAUNDERS, D. F. 1983. Rock classification by characteristics of aerial gamma-ray measurements, J. Geochem. Exploration, 18: 47-73.

HANSEN, D. A. 1975. Geological applications manual for portable gamma-ray spectrometers, Exploranium, Toronto, $87 \mathrm{p}$

JOST, H., CARMELO. A. C. \& MENEZES, P. R. 1994. Litologias, relações de contato e estrutura do Bloco Caiamar, Crixás, Goiás, In: SIMPOSIO DE GEOLOGIA DO CENTRO-OESTE, 4. Brasília, 1994, Ana/5... Brasília, SBG-DF. p. 18-20.

JOST. H. \& OLIVEIRA, A. M. 1991. Stratigraphy of the greenstone belt, Crixás region, Goiás, Central Brasil, J. of South Amer. Earth Sci., 4:201-204

JOST, H., VARGAS, M C FUCK, R A, KUYUMJIAN, R. M. \& PIRES, A. C. B. 1994. Relações de contato, litologias, geologia estrutural e geofísica do Bloco Arqueano do Moquém, Crixás, Goiás. In: SIMPÓSIO DE GEOLOGIA DO CENTRO-OESTE. 4. Brasília, 1994. Anais... Brasília, SBG-DF. p. 21-23.

JOST, H., VARGAS, M. C. GUGELMIN, W \& OLIVEIRA, S. R. M 1989. Seqüência Morro Escuro: uma nova unidade estratigráfica do Arqueano/Proterozóico Inferior na região de Crixás, Estado de Goiás, Rev. Bras. Geoc., 19:283-289.

KRAUSKOPF, K. 1967. Introduction to Geochemistry, McGraw-Hill Book Co., New York, $721 \mathrm{p}$

KUYUMJIAN, R. M. 1981. Geologia e mineralizações auríferas do greenstone belt da faixa Crixás, Goiás, Dissertação de Mestrado, UnB/Inst. de Geociências, 67 p.
MARINI, O. J. 1993. Filosofia do Programa Distritos Mineiros do DNPM e aerogeofísica prospectiva: o exemplo do Projeto Rio das Velhas, In CONGR. INTERN. DA SOC. BRÂS. DE GEOF, 3. Rio de Janeiro, 1993, Resumos Expandidos... Rio de Janeiro, SBGf, v. 1. p. 434-438.

MARINI. O. J.. FUCK, R. A., DARDENNE, M. A. \& DANNI. J. C. M. 1984, Província Tocantins, Setor Central e Sudeste, In: Almeida, F. F. M. e Hasui, Y. (Eds. ), O Pré-cambriano do Brasil. Edgar Blucher Ltda., S. Paulo.

NORWINE, J. R., HANSEN, D. J.. SAUNDERS, D. F. \& GALBRAITH J. H. 1980. Near surface moisture and biomass influences on the reliability of aerial radiometric surveys as a measure of natural radioelement concentrations, Preliminary report, U.S.D.E., Rep. GJBX-136(80).

PULZ, G. M. 1990. Geologia do depósito aurifero tipo Maria Lázara (Guarinos, Goiás). Dissertação de Mestrado, UnB/ Inst. de Geociências, 139 p.

ROWAN. L. C. GOETZ, A. F. H. \& ASHLEY, R. P. 1977. Discrimination of hydrothermally altered and inaltered rocks in visible and nearinfrared multispectral images, Geophysics, 42:522-535.

SANTOS FILHO, J. L.. ARAUJO. A. H. de \& CARVALHO Jr.. O. A. 1994. Expressão geofísica da alteração hidrotermal no greenstone belt de Guarinos. Goiás, In: SIMPOSIO DE GEOLOGIA DO CENTRO-OESTE, 4. Brasília, 1994. Anais... Brasília, SBG-DF. p. 92-94.

SAUNDERS, D. F., BRANCH. J. F. \& THOMPSON. C. K. 1994. Tests of Australian aerial radiometric data for use in petroleum reconnaissance, Geophysics, 59:411-419.

SAUNDERS. D R. BURSON. K. R. BRANCH. J. F \& THOMPSON. C. K. 1993. Relation of thorium-normalizaed surface and aerial radiometric data to subsurface petroleum accumulations. Geophysics, 58:1417-1427.

SAUNDERS. D. F. TERRY. S. A. \& THOMPSON. C. K. 1987. Test of National Uranium Resource Evaluation gamma-ray spectral data in petroleum reconnnaissance, Geophysics, 52:1547-1556.

SUSZCZYNSKI. E. F. 1973. Mapa metalogenético do Brasil. MME/ DNPM, Rio de Janeiro. $19 \mathrm{p}$.

THOMSON. M. L. 1986. Petrology of the Crixas gold deposit, Brazil: Evidence for gold associated with hydrotermal alteration, subsequent to metamorphism, In: Gold 86 Symposium, Proceedings... Toronto, p. 284-296.

THOMSON, M. L. 1991. Multiphase deformation and metamorphism of the Crixas greenstone belt, Goias, Brazil: evidence from poikiloblast inclusion trails and metamorphic mineral assemblages, J. of South Amer. Earth Sci., 4:119-130.

TRAVASSOS. J. M. \& PIRES. A. C. B. 1994. The screening effect of a tropical forest on airborne gamma-ray spectrometry, Nucl. Geophy., 8:461-471

VARGAS, M. C. 1992. Geologia das rochas granito-gnáissicas da região de Crixás, Guarinos, Pilar de Goiás e Hidrolina. Dissertação de Mestrado, UnB/Inst. de Geociências, 172 p.

WARD, S. H. 1981. Gamma-ray spectrometry in geologic mapping and uranium exploration, In: Skinner, B. J. (Ed.). Econ. Geol., 75th anniversary volume, p. 840-849.
MANUSCRITO A832

Recebido em 14 de marco de 1995

Revisão do autor de 31 de janeiro de 1996 Revisão aceita em 20 de marco de 1996 